\title{
AND KNOWLEDGE SPACE BASED \\ ON EPO PATENTS
}

\section{Jana Vlčková, Nikola Kaspř́íková*}

\begin{abstract}
:
How is knowledge distributed over space and how are different types of knowledge related? These questions have so far received little attention. In this paper we measure knowledge relatedness based on the relationship between individual patent categories by using coclassification information obtained from EPO patents. We also follow specialization of countries and its evolution over the past three decades. We focus on the EU, the United States and China. The objective of this paper is to identify the knowledge relatedness between technological fields and to map knowledge produced in selected countries. For visualization of knowledge relatedness network analysis has been used.
\end{abstract}

Keywords: patents, knowledge relatedness, knowledge space, network analysis, EPO patents, technological advantage

JEL Classification: O30, R12, D83

\section{Introduction}

The importance of knowledge and capabilities for economic development of nations, states, and even individual firms is undoubted. It is also well known that new knowledge can support growth as well as decline of some firms and regions through the processes of creative destruction. Despite of that, it is not known which type of knowledge is of a key importance. Innovation activity is unevenly distributed over space. This is to a large part attributable to limited diffusion of tacit knowledge over larger distances (Gertler, 2003).

Regions differ in their technological levels and the type of industry that is concentrated therein. Successful regions are able to create and use various types of knowledge which is the main source of their competitive advantage. The case studies aimed at particular regions (e.g. Cooke et al., 1997; Saxenian, 1996) focus on specific conditions in these regions. However, these conditions are difficult to generalize, because they are unique for the region. Regional differences were identified in manufacturing techniques (Rigby and Essletzbichler, 2007) and organizational procedures (Storper, 1997), though, there is no systematic evidence about what type of knowledge is created in particular regions and what type of knowledge is important for specific activities.

* Jana Vlčková, Faculty of International Relations, University of Economics, Prague, Czech Republic (jana.vlckova@vse.cz),

Nikola Kaspříková, Faculty of Informatics and Statistics, University of Economics, Prague, Czech Republic, (nikola.kasprikova@vse.cz). 
Knowledge relatedness is often used to assess how specialization and diversity affect economic growth. Several studies aim at knowledge relatedness or coherence at the firm level. Most of them focus on the connection between technological diversification and firms' technological performance (e.g. Tanriverdi and Venkatraman, 2005; Makri et al., 2009; Leten et al., 2007). This is often closely related to absorptive capacity of firms, which Cohen and Levinthal (1990) describe as "an ability to recognize the value of new information, assimilate it, and apply it to commercial ends" (p.128). The importance of specialization and diversity for economic growth has also been questioned within the recently developed concept of related and unrelated variety (Frenken et al., 2007). Most of these studies confirm that knowledge should be similar enough to enable learning and at the same time different enough to provide new opportunities to explore. Thus complementary knowledge seems to be the most important for economic growth. At the regional level the importance of specialization and diversity for economic growth revolves around the impact of Jacobian and MAR externalities. However, as Beaudry and Schiffauerova (2009) have presented in their review paper, substantial academic support for the positive impact of both MAR (specialization) and Jacobs (diversity) externalities on regional performance have been provided.

Patents produced by people from individual countries represent the knowledge available in a given area. This knowledge is being developed continuously and is affected by several actors including firms and research organizations, institutional context and linkages between individual actors (Nelson, 1993). Patents can be used to identify the relationship between individual industries based on the relationship between individual patent categories and also to identify the specialization of countries or regions on specific technological fields. Thanks to usage of patent data for several years the development of technological specialization can be followed.

With respect to technology and innovations, the EU is lagging behind the United States and Japan. Despite pronounced goal to become "the most competitive and dynamic knowledge-based economy", the EU as a whole has not improved its competitiveness over the last years, rather the opposite. Recently, emerging economies like China have started to increase their technological capabilities.

In this paper we focus on technological relatedness of individual technological fields measured by patents. The aim of the paper is, firstly, to measure the variety of knowledge and "relatedness" between technological fields. Secondly, we map the type of knowledge produced in individual countries or regions and how it evolved over the past three decades. Main attention is given to the EU and a comparison of the situation therein to the United States and China. Knowledge relatedness and knowledge space based on patents can be used not only to show the specialization of regions, but also to identify technological fields "related" to those that are already present in the regions' knowledge base. By focusing on technological fields that are closest to the ones already represented in the region, the knowledge assets should be extended more effectively.

To measure the knowledge relatedness we follow the method introduced by Kogler et al. (2013) and use the probability that one patent belongs to several technological (patent) categories. We use granted European patents (EPO) and for one specific year also granted USPTO patents to measure knowledge relatedness and construct the knowledge space.

In the first section data is described. This section also includes some basic facts about patents and patent system. Next chapter includes methodology. In the third chapter results are shown. Last section concludes. 


\section{Data}

For measuring knowledge relatedness and creation of knowledge space, the patent data from EPO PATSTAT database will be used which includes patents from the whole world. The patents produced in a country and its classification to a patent category reflect the underlying knowledge base present in the area. In the analysis the patents from two patent systems will be used. For all years the network is built based on EPO patents, the USPTO patents will only also be used for 2005 . Using both patent systems allows comparison and at the same time it enables us to follow the position of regions in these two different patent systems. Both the US and European markets are developed, the main difference is that in the case of USPTO patents the American inventors will be "favoured", since over half of the inventors come from the US, and vice versa for European patents.

The patents have been used as an indicator of innovation activity since the 1960s. Schmookler (1966) was the first to assign patents to industrial sectors. Based on the comparison of direct measures of innovation activity and patents Acs and Audretsch (1989) and Acs et al. (2002) proved that patents are a reliable measure of innovation in economic sectors as well as at state and regional level. Later, based on empirical analysis performed on a sample of 34 countries de Rassenfosse and van Pottelsberghe (2008) have found a high correlation between patent numbers and R\&D performance at the country level. Patents have been used in many other studies with different research focus (e.g. innovation networks and knowledge spillovers, emerging technological fields). Patent data are available for most countries over long periods. Most of the important inventions are patented. Patents offer other useful and detailed information regarding the inventors and owners which are openly available.

On the other hand, not all innovations are patented, not all inventions are patentable and not all patentable inventions are patented (Acs and Audretsch, 1989). There are differences between individual countries and sectors in the rate of patenting ${ }^{1}$. Allocation of patents to individual economic sectors is not easy. Patent classification does not correspond with classification of economic activities and thus within chemistry, an invention can be a fertilizer as well as pharmaceuticals. Another question concerns the relevance of sectors. Is it the one, that created and produced the invention (R\&D expenditures), or the one which will use the final product and whose productivity will increase (Griliches, 1998)?

The three most important patent offices are the European Patent Office (EPO), the US Patent Offices (USPTO) and the Japanese Patent Office (JPO). Unlike USPTO and JPO, EPO is a regional patent office which includes 38 member states. Even if a patent is granted at the regional level, it must be validated in each member state. EPO patents can originate directly at EPO office, without any priority application ${ }^{2}$ being made anywhere in the world. Secondly, EPO can be an extension of national patent. Thirdly, it can be international patent applied through $\mathrm{PCT}^{3}$ procedure. The knowledge space should be ideally created based on patents from the whole world. However, there are huge differences between patent systems and thus combining patents from different patent offices is not appropriate. International

\footnotetext{
1 Firms in high and medium-high tech manufacturing industries create $56 \%$ of patents, in mediumlow tech it is around 7\% and in business services it is around 30\% (OECD, 2012).

2 Priority patent application is the first application for an invention made anywhere in the world. The date the priority application is called the priority date.

3 Patent Cooperation Treaty - international patent application.
} 
(PCT) patents are an option for a patent which needs not be made. Further, increase of PCT patents can be observed mostly from 1990, thus using them is not suitable.

Patents do not measure the economic value (Hall et al., 2001). The value of most patents is negligible. However, we are interested in the technological relatedness, not the economic value. Thus using simple counts is sufficient. Only approved patents are included in the analysis, both in case of EPO 4 and USPTO patents. Patents are aged by the year of application, since it is closest to the date of invention. The development of knowledge relatedness will be followed in 1985, 1995 and 2005. The 10-year lag enables us to observe more pronounced changes. The last year was set to 2005, due to the time lag between the application and grant, patents applied in later years might not have been decided yet. The country of inventor is used rather than the country of the patent owner, since we are interested in innovation capabilities of a country. If multiple inventors are assigned the country of the first listed inventor is used.

The knowledge relatedness is measured based on the patent categories in which the patents belong to. Each patent is placed into one or more patent categories which reflect technological characteristics of the underlying knowledge. Patent systems use different categories. International classification of patents (IPC) is divided into 70,000 categories, these categories are hierarchically divided into 8 sections, 20 subsections, 221 classes, 616 subclasses etc. USPTO uses USPC, which has 160,000 subcategories. The classification is being regularly updated through reclassification, though neither of these reclassifications are quick enough to respond to new trends.

In IPC classification an applicant classification approach prevails, in USPC it is the functional approach in combination with applicant approach ${ }^{5}$ and this system is more elaborate. USPTO patents are in the PATSTAT database also reclassified to IPC. Though concordance tables exist, due to big differences in both patent classifications these tables will not be completely precise. The other difference is related to the fact that USPC always has one priority category. The main disadvantage of patent classification is the fact that patent classes and subclasses are not easily attributable to technology fields like ICT or biotechnology. In order to do that, highly disaggregated classification must be used in combination with text search.

In further analysis we use IPC classification divided into 121 classes. More detailed classification is less suitable for network analysis. One patent can thus belong to several subclasses of one class. Each patent is placed on average to 1.5 categories. Over time this number decreases; more than half of the patents belonged to only one category, in 2005 it was over $70 \%$. We focus on 3 countries/regions and its technological advantage: the EU, the USA and China.

\section{Methods}

Technological relatedness can be measured by various indicators. First attempts to measure technological or knowledge relatedness ${ }^{6}$ have been done by Scherer (1982) or Jaffe (1986).

4 The grant is only at the EPO level - indicating fulfillment of all required conditions. Each patent must be then validated in individual European countries.

5 Applicant approach prefers the field, where the patent will be used; functional approach is more related to the field, where the invention/process belongs to.

6 These measures are used as indicators of specialization and diversity, relatedness and coherence. For complete definition see Larsson and Finkelstein's (1999). 
Several methods have been used to identify the relationship between individual industries so far. Some of them measure the probability of relations between technological fields of individual patents e.g. Breschi et al. (2003) or use patent citations to follow the relationship between technological performance of firms and their technological diversification (Leten et al., 2007). Other studies combine patent data with spatial data (Kogler et al., 2013).

While preparing the knowledge space we will use similar method as Hidalgo et al. (2007). They measured the distance between individual products in international trade based on the co-exporting of these products by individual countries. According to them specialization of a country is related to knowledge and capabilities present in a given country. Therefore it is easier to start producing certain products that are close to products in the "product space" that are already produced than to products that are more remote and require quite different knowledge and capabilities. Similar findings have been detected at the firm level by Breschi et al. (2003): "Firms follow a coherent pattern of technological diversification, which clusters around groups of technologies that share a common or complementary knowledge base, rely upon common scientific principles or have similar heuristics of search" (p. 70).

We use granted EPO patents to measure the technological relatedness. The relatedness between individual patent categories is measured based on co-occurrence of these categories in particular patents. We suppose that the more often a patent belongs to two different patent categories the higher is the probability that these patent categories share similar knowledge base. The aim of the knowledge space is to map how individual categories are related and follow the development trajectory of technological fields. At first, it is necessary to prepare a symmetric matrix which includes the number of patents belonging to particular categories.

Table 1 | Example of Patent Matrix

\begin{tabular}{|l|r|r|r|r|r|r|}
\hline Classification & A01 & A21 & A22 & A23 & A24 & A41 \\
\hline A01 & 3,830 & 3 & 6 & 37 & 8 & 6 \\
\hline A21 & 3 & 137 & 1 & 33 & & \\
\hline A22 & 6 & 1 & 104 & 14 & & \\
\hline A23 & 37 & 33 & 14 & 413 & & 1 \\
\hline A24 & 8 & & & & 82 & \\
\hline A41 & 6 & & & 1 & & 410 \\
\hline
\end{tabular}

Source: EPO, 2011 - own calculation

This matrix of co-occurrences can then be used to derive a measure of relatedness between technological fields and visualization of relations between patent classes in the networks. Overall there are 121 patent classes, belonging to 8 sections. We apply the same method as Kogler et al. (2013); we measure the knowledge relatedness based on the probability that individual patent belongs to more categories. Let $P$ be the number of granted patents, let $p$, where $p=1,2, \ldots \mathrm{p}$, be a particular patent and $i$ and $j$ patent categories. If a patent belongs to a category $i$, then $F_{i p}=1$. If a patent does not belong to category $i$ 
$F_{i p}=0$. The number of patents for a category $i$ is $N_{i}=\sum_{p} F_{i p} \cdot N_{i j}=\sum_{p} F_{i p} F_{i j}$ indicates the number of patents belonging to both category $i$ and category $j$. This is done for all 121 categories and finally, there is a $121 \times 121$ matrix, which indicates the number of patents belonging to both categories. For example in 2005 there are 6 patents belonging to category A22 as well as category A01: (see Table 1).

Since the knowledge relatedness is affected not only by the number of patents with co-occurrence of the two different categories but also total number of patents belonging to a category, this must be also taken into account. Therefore a standardized matrix of cooccurrence which indicates technological relatedness between two different categories in a year is created with the elements:

$$
S_{i j}=\frac{N_{i j}}{\sqrt{N_{i} * N_{j}}} ;
$$

Where the elements on the main diagonal of the matrix $\mathrm{S}$ are set to 1 .

For every year the knowledge relatedness between all categories was computed. This knowledge relatedness is then used for the construction of knowledge networks (the knowledge space) and visualization of relations between individual categories with the help of Cytoscape software. Nodes represent patent categories; the size of the nodes indicates the number of patents belonging to that category. Nodes belonging to the same sections are marked with the same color and shape (see Figure 1). Only the strongest relations are mapped $^{7}$. The bio-layout has been chosen for the visualization of the network ${ }^{8}$.

Except for the whole knowledge space built based on all EPO patents, the position of individual countries/regions in particular technological fields is also mapped. For all countries in all years the so called revealed technological advantage ${ }^{9}$ is mapped (OECD, 2009) based on a simple formula:

$$
R T A=\left(P_{i c} / P_{I C}\right) /\left(P_{i C} / P_{I C}\right)
$$

Where $P$ indicates the number of patents, $P_{i c}$ is the number of patents in the category $i$ and country $c, P_{I c}$ is the total number of patents in category $i$ in all countries. $P_{i C}$ is the number of all patents in a country $c$ and $P_{I C}$ is the number of all patents in all countries.

If RTA is equal to 0 , the country does not have a patent in the technological field, RTA over 1 indicates specialization in the technological field. For all years a network from 2005 is used, otherwise it would not be possible to observe development of technological specialization over time. If a country has RTA in the patent category (RTA is $>1$ ), it is marked in black.

The knowledge relatedness measures the relation between two patent categories. The average knowledge relatedness score in a country is a place-based measure of total technological similarity between all pairs of patents invented in the country divided by the number of such pairs. It is a measure of specialization. It also enables the comparison of

$7 \quad 1,000-1,500$ relations from 2,000-3,000, the cut-off point is set according to histogram.

8 The algorithms used for the design of the layout of the network are described in the following document: http://wiki.cytoscape.org/Cytoscape_3/UserManual\#Cytoscape_3.2BAC8UserManual.2BAC8-Navigation_Layout.Automatic_Layout_Algorithms.

9 It is an analogy to revealed comparative advantage used in international trade or the so called location quotient. 
knowledge relatedness in patent sections or over time. The average knowledge relatedness for a year $t$ and country $c$ is calculated as:

$$
A R^{t, c}=\frac{\sum_{i} \sum_{j} S_{i j}^{t} * D_{i j}^{t, c}+\sum_{i} S_{i i}^{t} * 2 D_{i i}^{t, c}}{N^{t c} *\left(N^{t c}-1\right)} \text { for } \mathrm{i} \neq \mathrm{j},
$$

Where $S_{i j}^{t}$ is the knowledge relatedness between patents in classes $\mathrm{i}$ and $\mathrm{j}, D_{i j}^{t, c}$ indicates the number of pairs of patents belonging to category $i$ and $j$ in a year $t$ and country $c$, $N^{t c}$ is the total number of patents in a year $t$ and country $c$.

Higher average knowledge relatedness shows that patents are in the knowledge space closer to one another, meaning that these patent categories tend to co-occur with higher frequency. Average knowledge relatedness thus indicates the coherence of the knowledge base in the country.

\section{Technological Relatedness and Knowledge Space}

\subsection{Number of patents and knowledge relatedness}

From 1985 to 1995 there is an increase in the number of EPO granted patents, up to 2005 there is a decrease. This is probably related to the fact that in case of all patents applied for in 2005 the decision must not have been made, although the average time for decision in the case of EPO patents is 39 months. In 2005 there is also a decrease of the average number of categories per patent and in average relatedness (see Table 2). In case of USPTO patents both granted patents and average number of categories per patent increased between 1975 and 2005, however, there was also a small drop in average knowledge relatedness between 1995 and 2005 (Kogler et al., 2013). The differences are probably caused by the decreasing average number of patent categories an EPO patent belongs to in 2005 as well as differences between patent classification systems (primary category in USPC classification).

Table 2 | EPO Patents in 1985, 1995 and 2005

\begin{tabular}{|l|c|c|c|}
\hline Year & $\begin{array}{c}\text { Granted } \\
\text { patents }\end{array}$ & $\begin{array}{c}\text { Average number of categories } \\
\text { per patent }\end{array}$ & $\begin{array}{c}\text { Average knowledge } \\
\text { relatedness }\end{array}$ \\
\hline $\mathbf{1 9 8 5}$ & 28,775 & 1.63749 & 0.0532 \\
\hline $\mathbf{1 9 9 5}$ & 46,166 & 1.65912 & 0.0566 \\
\hline $\mathbf{2 0 0 5}$ & 31,614 & 1.34978 & 0.0491 \\
\hline
\end{tabular}

Source: EPO, 2011 - own calculation 
In the observed period there is an increase of EPO patents from the EU15 of more than $7 \%$. In 1995 the USA were the country with the most EPO granted patents ${ }^{10}$ with over $26 \%$, in 2005 it decreased to $15 \%$ and Germany took the lead (see Table 3). A significant increase has occurred among inventors from South Korea ( $8^{\text {th }}$ position) and China ( $14^{\text {th }}$ position), which confirms the rising economic as well as technological importance of emerging Asian economies. New Member States of the EU (EU12+) account for only $0.5 \%$ of all patents.

Table 3 | EPO Patents Based on Inventors' Country in 1985, 1995 and 2005

\begin{tabular}{|l|c|c|c|c|c|c|}
\hline \multirow{2}{*}{ Country } & \multicolumn{2}{|c|}{1985} & \multicolumn{2}{c|}{1995} & \multicolumn{2}{c|}{2005} \\
\cline { 2 - 7 } & $\begin{array}{c}\text { Number } \\
\text { of patents }\end{array}$ & In (\%) & $\begin{array}{c}\text { Number } \\
\text { of patents }\end{array}$ & In (\%) & $\begin{array}{c}\text { Number } \\
\text { of patents }\end{array}$ & In (\%) \\
\hline EU & 14,583 & $50.7 \%$ & 21,888 & $47.4 \%$ & 18,221 & $57.6 \%$ \\
\hline US & 6,848 & $23.8 \%$ & 12,182 & $26.4 \%$ & 4,812 & $15.29 \%$ \\
\hline CN & 24 & $0.1 \%$ & 21 & $0,0 \%$ & 403 & $1.3 \%$ \\
\hline
\end{tabular}

Source: EPO, 2011 - own calculation

Regarding the number of patents ${ }^{11}$, the two biggest sections are Performing operations; transporting and Chemistry; metallurgy with over $20 \%$ of all patents (see Table 4). The smallest sections are Textiles; paper and Fixed constructions with c. $3 \%$. Over the 20 years the highest increase is in sections Human necessities and Performing operations; transporting (over 25\%). The latter sections include classes that represent newer technologies, such as aircraft or nanotechnology. A significant decrease is in section Chemistry; metallurgy (a drop to almost a half) and Textiles; paper.

The average relatedness has been likewise calculated for patent sections ${ }^{12}$. We anticipate that average relatedness between patent sections should exhibit higher levels. Obviously, this is true for all sections. For most sections, the average knowledge relatedness has increased over time. The highest relatedness is in sections Human necessities and in 2005 in Electricity. The lowest is in Performing operations; Transporting and Physics.

In order to compare the differences between USPTO and EPO patents we built the knowledge space for 2005 based on both systems. In USPTO there are five times more granted patents. The number of categories per patent and average knowledge relatedness is also higher ${ }^{13}$. The major differences are in the number of patents per patent sections, e.g. around $30 \%$ are in sections Physics and Electricity and only $14 \%$ of patents belong to section Performing operations; Transporting. This is likely caused by the reclassification from USPC to IPC.

10 Based on inventors.

11 These numbers are relativized, thus if a patent belongs to two sections, the number of patent per section is 0.5 .

12 This relatedness is thus calculated for the patents that only belong to the patent categories within these sections.

13 Average knowledge relatedness based on USPTO is 0.0798 , whereas for EPO it is 0.0492 . 


\begin{tabular}{|l|c|c|c|c|c|c|c|}
\hline & \multirow{2}{*}{ Sections } & \multicolumn{2}{|c|}{1985} & \multicolumn{2}{c|}{1995} & \multicolumn{2}{c|}{2005} \\
\cline { 3 - 8 } & $\begin{array}{c}\text { Number } \\
\text { of cate- } \\
\text { gories }\end{array}$ & $\begin{array}{c}\text { Granted } \\
\text { patents } \\
\text { (rel.) }\end{array}$ & $\begin{array}{c}\text { Average } \\
\text { know- } \\
\text { ledge } \\
\text { related- } \\
\text { ness }\end{array}$ & $\begin{array}{c}\text { Granted } \\
\text { patents } \\
\text { (rel.) }\end{array}$ & $\begin{array}{c}\text { Average } \\
\text { know- } \\
\text { ledge } \\
\text { related- } \\
\text { ness }\end{array}$ & $\begin{array}{c}\text { Granted } \\
\text { patents } \\
\text { (rel.) }\end{array}$ & $\begin{array}{c}\text { Average } \\
\text { know- } \\
\text { ledge } \\
\text { related- } \\
\text { ness }\end{array}$ \\
\hline Human necessities & 15 & 3,510 & 0.3156 & 6,605 & 0.4037 & 4,832 & 0.3556 \\
\hline $\begin{array}{l}\text { Performing operations; } \\
\text { transporting }\end{array}$ & 36 & 5,893 & 0.0956 & 9,633 & 0.1122 & 8,195 & 0.1362 \\
\hline Chemistry; metallurgy & 20 & 5,880 & 0.2212 & 7,995 & 0.2292 & 3,675 & 0.2115 \\
\hline Textiles; paper & 8 & 715 & 0.1455 & 984 & 0.1191 & 574 & 0.2061 \\
\hline Fixed constructions & 7 & 1,000 & 0.1724 & 1,407 & 0.1466 & 988 & 0.1972 \\
\hline $\begin{array}{l}\text { Mechanical engineering; } \\
\text { lighting; .... }\end{array}$ & 17 & 2,793 & 0.2112 & 4,279 & 0.2137 & 3,632 & 0.2384 \\
\hline Physics & 13 & 4,783 & 0.1211 & 7,781 & 0.1411 & 4,334 & 0.1052 \\
\hline Electricity & 5 & 4,193 & 0.1291 & 7,470 & 0.1792 & 5,382 & 0.2732 \\
\hline
\end{tabular}

Source: EPO, 2011 - own calculation

Note: The patent counts are relativized based on the number of patent classes the patent belongs to.

\subsection{Knowledge relatedness and knowledge space}

In this section the knowledge space will be described. In Figure 1 the knowledge space for 2005 is displayed. Altogether 121 patent classes are mapped, the node size indicates the number of patents per patent class and the color and shape the patent section the class belongs to. The thickness of the lines describes the strength of the relations. In general knowledge relatedness should be higher between classes that share similar type knowledge. There is a clear evidence of clustering of patent classes from Electricity and Physics section (right down corner). This close relationship indicates that patents tend to co-occur in classes belonging to these two sections. Thus these sections use similar type of knowledge and are complementary to each other. Since both of these sections represent fields with rather high requirements on research and development, which are connected with more sophisticated technology they can have in general higher technological and possibly also economic impact. Another small cluster can be found in the right upper corner which is far apart from other nodes and contains patents from Textiles; paper section. The patents under section Mechanical engineering; lighting; .... are more spread, to a certain part they concur to the section Chemistry; metallurgy. On the other hand, patents under sections Human necessities and Performing operations; transporting are among the most spread in the knowledge space. These two sections have one common feature, they include various fields that often do not relate to each other. For example the section Human necessities includes class A01-Agriculture, forestry... or A61-Medical or veterinary science. Under Performing operations; transporting classes like B61-Railways or B82-Nanotechnology can be found. Further, this section has the most classes and very low average knowledge relatedness. 


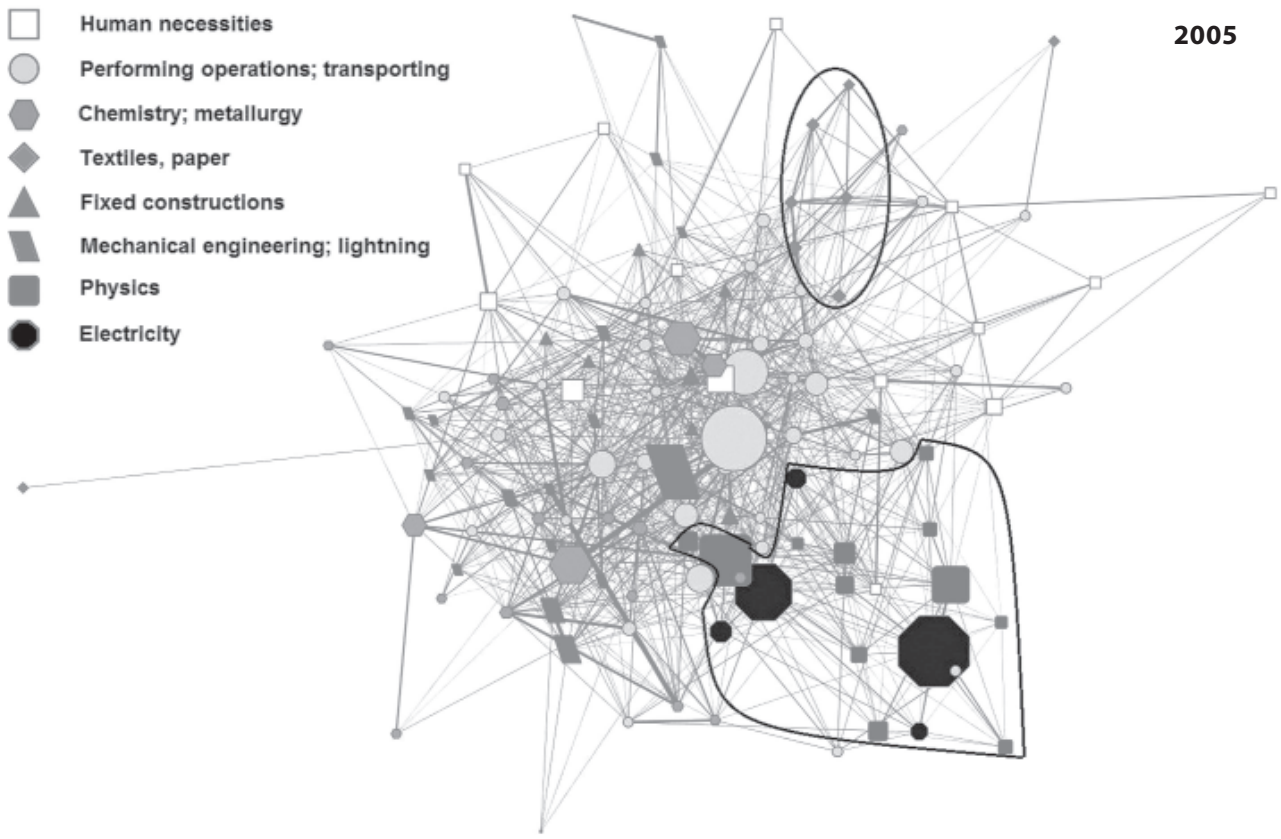

Source: EPO, 2011 - own calculation

In Figure 2 knowledge space for 1995 and 1985 is mapped. The number of relations is the highest in 1995. In this year there are more links and the nodes are bigger due to highest number of patents from all three years ${ }^{14}$. Since 1985 there is a bigger tendency of classes to cluster within individual sections. Over time, more significant separations of clusters can be observed in Textile; paper and Physics and Electricity sections. This indicates rising coherence between these sections. From the perspective of regions or firms, it means that it is more efficient to extend the knowledge base in Physics, if it is already patenting in Electricity section than e.g. in Chemistry; metallurgy. There is also higher tendency to cluster in case of patent classes from section Fixed constructions.

The knowledge space was also prepared for USPTO patents. The differences between both figures are mainly in the node sizes (especially in the sections Physics and Electricity). There are also two clusters; Physics and Electricity (on right side) and Textiles; paper (on the left side). Another cluster is emerging in the section Fixed constructions. The biggest difference is in patent classes from section Mechanical engineering; lighting. These classes are much more diffusing into Physics and Electricity classes than in case of EPO patents. The reason is probably differences between classifications.

14 On average $56 \%$ of all relations are included in figures. 
Figure 2 | Knowledge Space Based on EPO Patents in 1995 and 1985
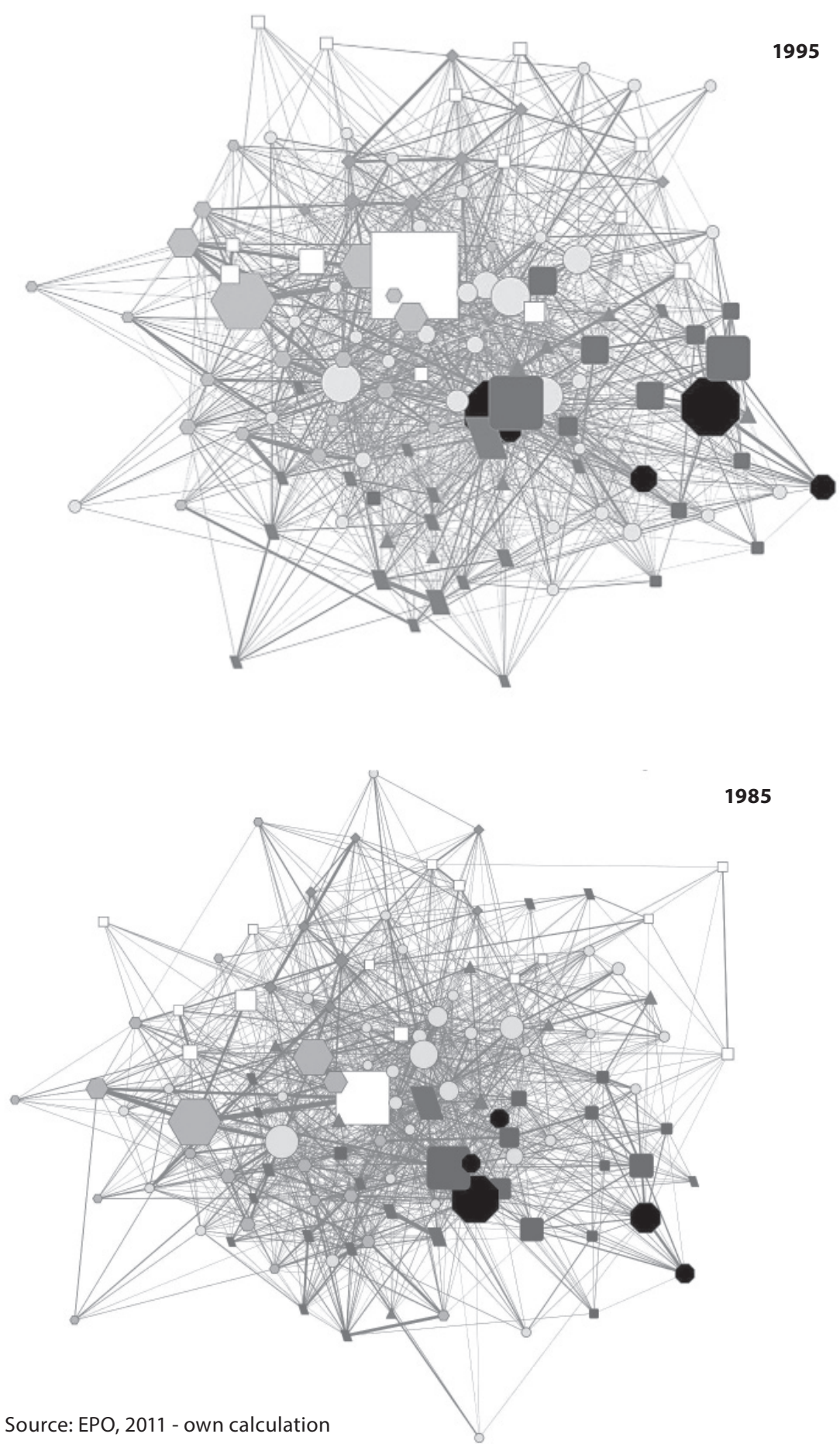

1985 


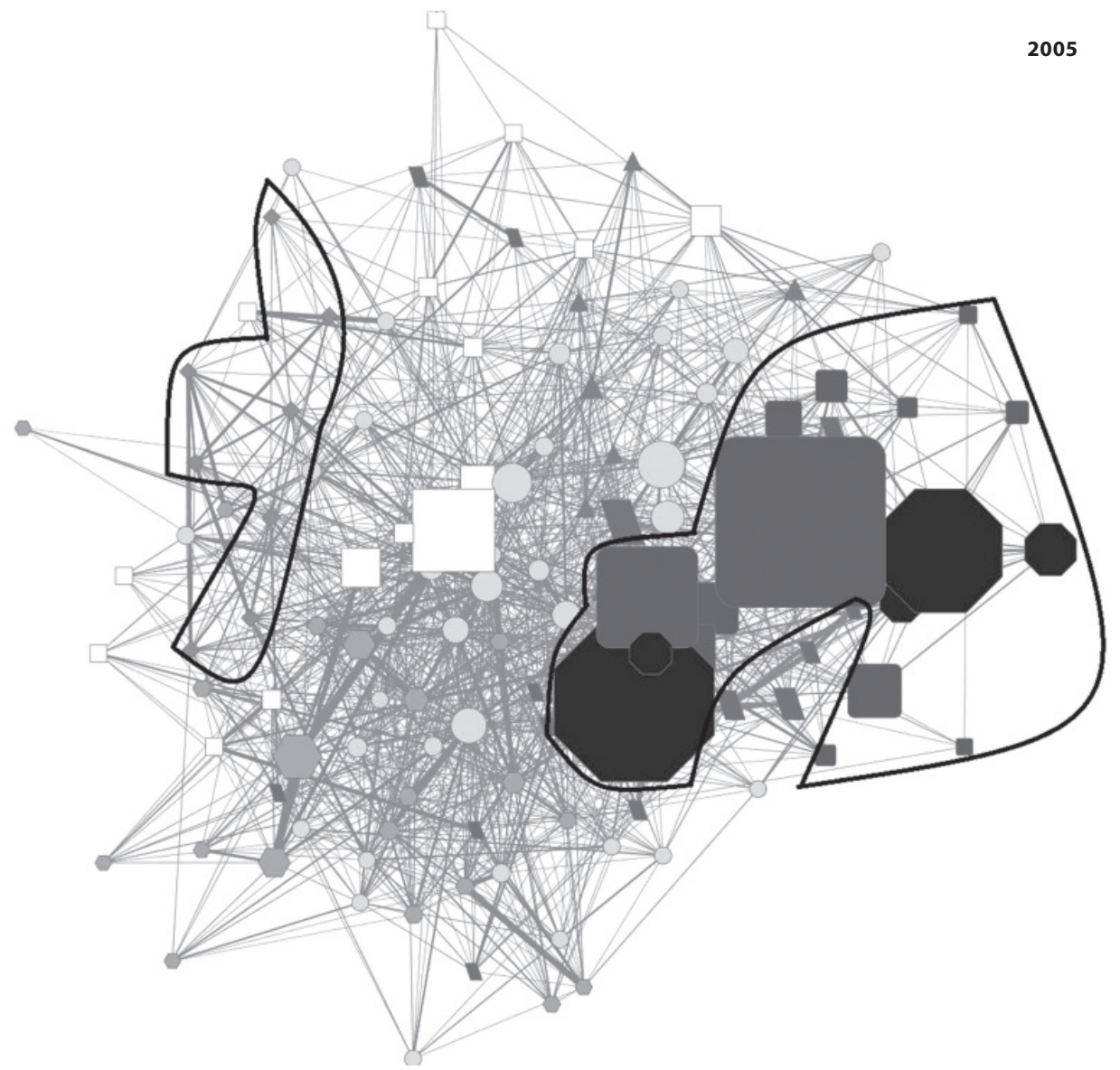

Source: EPO, 2011 - own calculation

\subsection{Knowledge space and knowledge relatedness in regions}

In this part we focus on the position of individual regions in technological sectors based on comparative (technological) advantage. The distribution of patents in a region reflects the underlying knowledge base and thus it enables us to follow changes in technological advantage in these regions over the three decades. We will also map the evolution of knowledge relatedness which measures the total technological distance between all pairs of patents within individual regions.

There are no significant changes in average knowledge relatedness over the period in regions except for China. However, this is related to the very few patents from China before 2005. China is the most specialized region since it has patents in a limited number of patent categories. There is a drop in average relatedness in all regions in 2005 which is consistent with the average relatedness score computed for the whole knowledge space. Over the years the USA remains to be significantly more specialized than the EU. As Kogler et al. (2013) have proved on the level of metropolitan areas, higher levels of specialization are connected 
with higher rate of patenting. But so far the discussion is still open, some studies support the importance of specialization (MAR externalities) others diversity (Jacobs externalities) for economic growth (see Beaudry and Schiffaerova, 2009). However, concept of related variety (Frenken et al., 2007) supports similar views as those at the firm level, diversity is important, but in complementary fields.

Table 5 | Average Knowledge Relatedness in Regions in 1985, 1995 and 2005

\begin{tabular}{|l|c|c|c|c|c|c|}
\hline \multirow{2}{*}{ Country } & \multicolumn{2}{|c|}{1985} & \multicolumn{2}{c|}{1995} & \multicolumn{2}{c|}{2005} \\
\cline { 2 - 7 } & $\begin{array}{c}\text { Number } \\
\text { of patents }\end{array}$ & $\begin{array}{c}\text { Average } \\
\text { knowledge } \\
\text { relatedness }\end{array}$ & $\begin{array}{c}\text { Numbers of } \\
\text { patents }\end{array}$ & $\begin{array}{c}\text { Average } \\
\text { knowledge } \\
\text { relatedness }\end{array}$ & $\begin{array}{c}\text { Numbers } \\
\text { of patents }\end{array}$ & $\begin{array}{c}\text { Average } \\
\text { knowledge } \\
\text { relatedness }\end{array}$ \\
\hline EU & 14,583 & 0.0459 & 21,888 & 0.0484 & 18,221 & 0.0451 \\
\hline USA & 6,848 & 0.0737 & 12,182 & 0.0855 & 4,812 & 0.0789 \\
\hline China & 24 & 0.0458 & 21 & 0.0702 & 403 & 0.3289 \\
\hline
\end{tabular}

Source: EPO, 2011 - own calculation

In order to follow the position of individual regions over the last three decades the knowledge space from 2005 is used and patent classes with technological advantage are marked in black. The figures are mapping technological advantage in EPO patents. EU has RTA in over half of patent classes due to the large number of patents from the EU. Therefore comparison with RTA in USPTO patents is reasonable. Comparison of RTA in EPO and USPTO patents is also interesting for China due to its limited number of EPO patents.

\section{United States}

Figure 4 | Evolution of Technological Advantage in United States
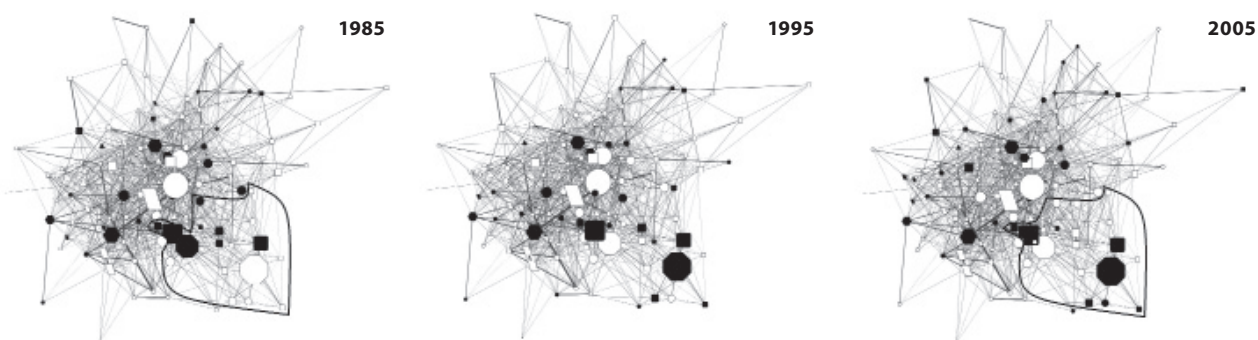

Source: EPO, 2011 - own calculatio. ,

Despite the fact that number of patents from US inventors has rapidly decreased (from $24 \%$ to $15 \%$ ), the number of classes with RTA has risen. Since 1985 there have not been significant changes except in Physics and Electricity sections (see Figure 4). Overall, the USA excels in sections Human necessities, Chemistry; metallurgy and Physics. With respect to individual patent classes their RTA is the strongest in E21-Earth or rock drilling; mining, F22-Steam generation and A61-Medical or veterinary science; hygiene. In USPTO 
patents US citizens invented over half of all patents in 2005 and have RTA in 70 from 121 patent classes. These classes belong to the same sections as in case of EPO plus section Fixed constructions ${ }^{15}$. The strongest RTA has the USA in USPTO in G07-Checking devices and F41-Guns.

\section{China}

Figure 5 | Evolution of Technological Advantage in China
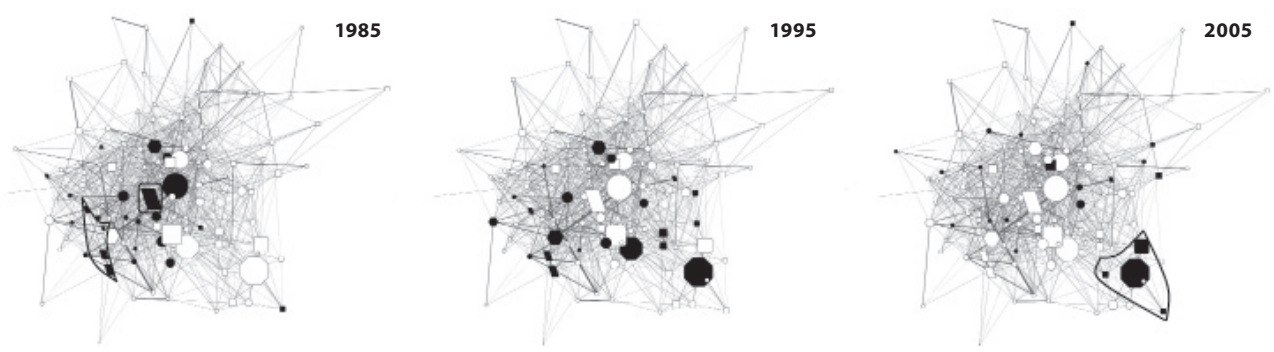

Source: EPO, 2011 - own calculation

In case of China there has been significant increase in the number of patents and patent classes with RTA between 1985 and 2005. Despite of that there are many classes where China has no patent. There is an obvious shift from section Mechanical engineering; Lightning.... to section Electricity (see Figure 5). China has significant RTA in sections H04-Electric communication technique or A47-Furniture, domestic articles or appliances... The share of Chinese inventors in EPO and USPTO patents is almost the same. In USPTO China has more classes with RTA, specifically in Electricity and also Textile; Paper. Due to the shift towards section Electricity, it can be expected that China will in future patent also in Physics, since both sections are tightly interconnected (require similar knowledge).

\section{European Union}

Figure 6 | Evolution of Technological Advantage in the EU
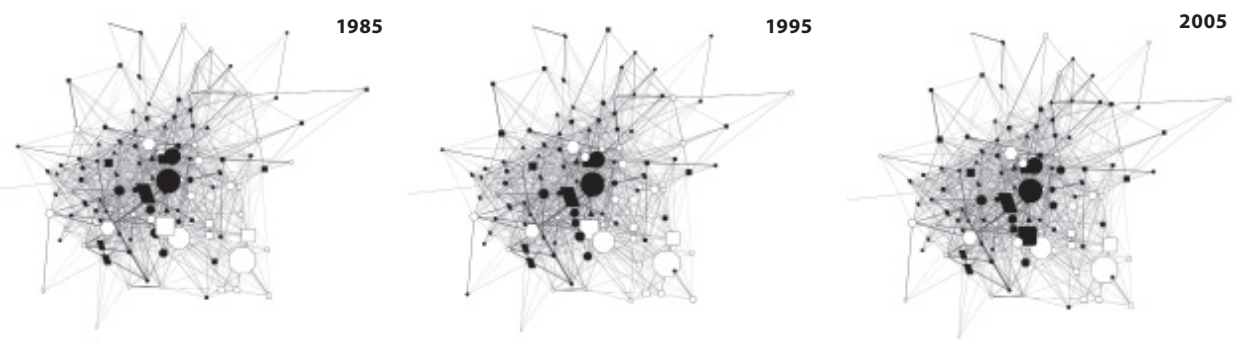

Source: EPO, 2011 - own calculation

15 Fixed constructions are much more tied to home economy, than for example consumer goods which are traded internationally. 
Since new Member States of the EU invented only a few patents, there is no difference in patent classes where the EU15 and the EU27 have revealed technological advantage. EU citizens invented over $60 \%$ of all patents, the EU has therefore RTA in most patent classes (over $70 \%$ ) and there have been only minor changes over the period. However, RTA is not distributed evenly across sections. The strongest RTA is in section Fixed constructions (reasons mentioned above). The EU is relatively lagging behind in sections Chemistry; metallurgy, Physics and Electricity. Significant RTA is for example in patent class G12Instrument details. In case of USPTO patens Europeans invented $11 \%$ of all patents. European inventors are lagging behind in the sections Physics and Electricity and excelling in sections Textiles; paper and surprisingly in Chemistry; metallurgy. Patent classes with RTA include both technologically less advanced procedures, e.g. C14-Skins; hides... or manufacturing of paper or textiles as well as more sophisticated procedures like $B 30$ Presses or B64-Aircraft; aviation; cosmonautics.

Innovations and technological development are one of the priorities of the EU, at least based on its pronouncement. However, there are many problems, including lower productivity, weak university-industry link and lower presence in industries like biotechnology or ICT (Dosi et al., 2005). The question is whether the EU should support these industries or whether it should choose several technological areas and build top research rather than investing in all fields. Considering the effectiveness of $\mathrm{R} \& \mathrm{D}$, the authors think that the EU should focus on technological fields where it already excels and on those that are close to the knowledge space, since these fields would require less effort.

Knowledge space indicates where a country has technological advantage but it can also be used to assess technological fields that share similar knowledge assets. For example the EU as a whole is lagging behind in Physics and Electricity. However, it is doing best at section Performing operations; transporting. Thus when considering the efficiency of R\&D efforts, the technological fields should be identified, which are closest to the fields where the EU excels. And since for example Physics and Electricity sections are further in the knowledge space, supporting research in these fields would be much more demanding. However, this is just an example of how the knowledge relatedness and knowledge networks could be used in policy making. It needs to be studied in more detail.

\section{Conclusion}

In most papers knowledge relatedness is either used to find out how specialization and diversity affect firms' performance or regional economic growth (e.g. Makri et al., 2009; Beaudry and Schiffaerova, 2009). However, we use the knowledge relatedness in this paper to map the knowledge space and identify changes in the specialization of selected regions.

The knowledge relatedness is measured by the co-classification of EPO patent grants to 121 patent classes following the method of Kogler et al. (2013). The average knowledge relatedness increased between 1985 and 1995 but dropped in 2005. Kogler et al. (2013) used US patents and observed an increase of average knowledge relatedness between 1995 and 2005 , though more modest than in earlier periods. This contrast can be caused by the drop of EPO patents in 2005 (not all patent applications were decided yet) as well as differences between classifications and should be further inspected.

Based on the knowledge relatedness the knowledge space has been created. In the knowledge space network several clusters emerge. The two most significant ones are 
the Textile; paper section and the other one includes patents from two sections; Electricity and Physics. This indicates that Electricity and Physics share similar knowledge base. Regarding the specialization of individual countries/regions, China has much higher average relatedness due to its limited number of patents. The United States is more specialized than the EU. The USA specializes in Human necessities, Chemistry; metallurgy and Physics, the EU is specialized in Performing operations; transporting and Fixed constructions. China has technological advantage in Electricity, in case of USPTO patents also in Textile; paper. China's significant increase of patents in section Electricity confirms increase of technological capabilities in the fields closely related to basic research and it can be expected that China will in future patent more in technologically advanced sections like Electricity and Physics.

Knowledge relatedness indicators and knowledge space cannot only be used to assess the effect of diversity and specialization on economic performance it can also be used to identify sectors which are closer to the knowledge base present in an economy. Although it is not yet clear, which combinations of technological classes are the most productive, it is more reasonable, to support technological research in fields proximate to current knowledge base. Countries should therefore focus on fields that are more technologically related to those the countries specialize in today, since these this fields use similar type of knowledge. Similarly as in the product-space concept (Hidalgo et al., 2011), the knowledge space can be also used to predict movement to new patent sections and abandonment of the old ones, that means to assess future technological trajectories. This would require more detailed classification and text search to identify specific economic sectors, since the IPC classification does not correspond to economic sectors. Nonetheless, these findings would be very useful for policy making.

\section{References}

Acs, Z., Audretsch, D. (1989), "Patents as a Measure of Innovative Activity." Kyklos, Vol. 42, No. 2, pp. 171-180.

Acs, Z. J., Anselin, L., Varga, A. (2002), “Patents and Innovation Counts as Measures of Regional Production of New Knowledge." Research Policy, Vol. 31, No. 7, pp. 1069-1085, http://dx.doi. org/10.1016/S0048-7333(01)00184-6

Beaudry, C., Schiffauerova, A. (2009), “Who's Right, Marshall or Jacobs? The Localization versus Urbanization Debate." Research Policy, Vol. 38, No. 2, pp. 318-337, http://dx.doi. org/10.1016/j.respol.2008.11.010

Breschi, S., Lissoni, F., Malerba, F. (2003), “Knowledge-Relatedness in Firm Technological Diversification." Research Policy, Vol. 32, No. 1, pp. 69-87, http://dx.doi.org/10.1016/S00487333(02)00004-5

Cohen, W. M., Levinthal, D. A. (1990), “Absorptive Capacity: A New Perspective on Learning and Innovation." Administrative Science Quarterly, Vol. 35, No. 1, pp. 128-152, http://dx.doi. org/10.2307/2393553

Cooke, P., Gomez Uranga, M., Etxebarria, G. (1997), “Regional Innovation Systems: Institutional and Organisational Dimensions." Research Policy, Vol. 26, No. 4, pp. 475-491, http://dx.doi. org/10.1016/S0048-7333(97)00025-5

De Rassenfosse, G., Van Pottelsberghe de la Potterie, B. (2009), "A Policy Insight into the R\&DPatentRelationship." Research Policy, Vol. 38, No. 5, pp. 779-792, http://dx.doi.org/10.1016/j. respol.2008.12.013 
Dosi, G., Llerena, P., Labini, M. S. (2005), “Evaluating and Comparing the Innovation Performance of the United States and the European Union." European Commission.

EPO (2011) EPO Worldwide Patent Statistical Database - Edition October 2011.

Frenken, K., Van Oort, F.,Verburg, T. (2007), “Related Variety, Unrelated Variety and Regional Economic Growth." Regional Studies, Vol. 41, No. 5, pp. 685-697, http://dx.doi. org/10.1080/00343400601120296

Gertler, M. S. (2003), "Tacit Knowledge and the Economic Geography of Context, or the Undefinable Tacitness of Being (there)." Journal of Economic Geography, Vol. 3, No. 1, pp. 75-99, http://dx.doi.org/10.1093/jeg/3.1.75

Griliches, Z. (1998), "Patent Statistics as Economic Indicators: A Survey." R\&D and Productivity: The Econometric Evidence (pp. 287-343), University of Chicago Press.

Hall, B. H., Jaffe, A. B., Trajtenberg, M. (2001), The NBER Patent Citation Data File: Lessons, Insights and Methodological Tools (No. w8498), National Bureau of Economic Research.

Hidalgo, C. A., Klinger, B., Barabási, A. L., Hausmann, R. (2007), “The Product Space Conditions the Development of Nations." Science, Vol. 317, No. 5837, pp. 482-487, http://dx.doi. org/10.1126/science.1144581

Jaffe, A. B. (1986), “Technological Opportunity and Spillovers of R\&D: Evidence from Firms' Patents, Profits and Market Value." American Economic Review, Vol. 76, No. 5, pp. 984-1001.

Kogler, D. F., Rigby, D. L., Tucker, I. (2013), “Mapping Knowledge Space and Technological Relatedness in US Cities." European Planning Studies, Vol. 21, No. 9, pp. 1-18, http://dx.doi.org $/ 10.1080 / 09654313.2012 .755832$

Larsson, R., Finkelstein, S. (1999), "Integrating Strategic, Organizational, and Human Resource Perspectives on Mergers and Acquisitions: A Case Survey of Synergy Realization." Organization Science, Vol. 10, No. 1, pp. 1-26, http://dx.doi.org/10.1287/orsc.10.1.1

Leten, B., Belderbos, R., Van Looy, B. (2007), "Technological Diversification, Coherence, and Performance of Firms." Journal of Product Innovation Management, Vol. 24, No. 6, pp. 567-579, http://dx.doi.org/10.1111/j.1540-5885.2007.00272.x

Makri, M., Hitt, M. A., Lane, P. J. (2010), “Complementary Technologies, Knowledge Relatedness, and Invention Outcomes in High Technology Mergers and Acquisitions." Strategic Management Journal, Vol. 31, No. 6, pp. 602-628, http://dx.doi.org/10.1002/smj.829

Nelson, R. (1993), “National Innovation Systems: AComparative Analysis.” University of Illinois at Urbana-Champaign's Academy for Entrepreneurial Leadership Historical Research Reference in Entrepreneurship.

Rigby, D. L., Essletzbichler, J. (2006), “Technological Variety, Technological Change and a Geography of Production Techniques." Journal of Economic Geography, Vol. 6, No. 1, pp. 45-70, http://dx.doi.org/10.1093/jeg/lbi015

OECD (2012), “OECD Science, Technology and Industry Scoreboard 2011.” OECD Publishing. Paris.

Saxenian, A. (1996), Regional Advantage: Culture and Competition in Silicon Valley and Route 128. Harvard University Press.

Scherer, F. M. (1982), "Inter-Industry Technology Flows and Productivity Growth." The Review of Economics and Statistics, Vol. 64, No. 4, pp. 627-634, http://dx.doi.org/10.2307/1923947

Schmookler, J. (1966), Invention and Economic Growth (Vol. 11), Cambridge, MA: Harvard University Press.

Storper, M. (1997), The Regional World: Territorial Development in a Global Economy. New York: Guilford.

Tanriverdi, H., Venkatraman, N. (2005), “Knowledge Relatedness and the Performance of MultiBusiness firms." Strategic Management Journal, Vol. 26, No. 2, pp. 97-119. 